\title{
FUSÕES E AQUISIÇÕES: APRENDENDO COM A EXPERIÉNCIA BRASILEIRA
}

RESUMO

Este artigo aborda as fusões e aquisições entendidas como processos, e relaciona a intenção de compra com as diferentes estratégias de integração. Apresenta um panorama dessas operações no Brasil, analisando de que forma a cultura local pode impactar esse processo. São apresentados os dados de uma pesquisa realizada com 106 empresas e sete estudos de caso. Os resultados indicam que um dos desafios dessas operações no país é o desenvolvimento adequado das etapas do processo, respeitando as características culturais locais. É reforçada a importância de fundamentar a escolha da estratégia de integração na motivação da compra ena situação da empresa adquirida. O s resultados também sugerem a existência de um modelo híbrido de gestão, influenciado pela cultura brasileira, que combina os processos racional izados das adquirentes com características de informalidade e de relações personalizadas das adquiridas.

\section{Betania Tanure}

Fundação Dom Cabral e PUC-Minas

\section{Vera L. Cançado}

Fundação Dom Cabral e Fundação Pedro Leopoldo/ Mestrado Profissional em Administração

\begin{abstract}
This paper contributes to the discussion of merger and acquisition as processes. It explores the relationship between the motivation for the purchase and different integration strategies. It presents a panorama of these operations in Brazil; and it analyzes in what way local culture can impact upon these processes. Data from research done at 106 companies in Brazil and from seven case studies are presented. The results indicate that one of the challenges to these operations in Brazil is the adequate development of the stages of the process. Local characteristics of informality and more per sonalized relationships should be respected. The paper confirms the importance of choosing an integration strategy that is based on the motivation for the acquisition and the situation of the acquired company. The results also suggest a hybrid model of management. This model is influenced by Brazilian culture and combines the rationalized processes of the acquiring companies with the informality and personalized relationship of the acquired companies.
\end{abstract}

PALAVRAS-CHAVE Gestão internacional, fusões e aquisições, aquisições transnacionais, integração cultural, cultura brasileira. KEYWORDS International management, mergers and acquisitions, transnational acquisitions, cultural integration, Brazilian culture. 


\section{INTRODUÇÃO}

As fusões e aquisições ( $F \& A$ ) apresentam a partir dos anos 1990 um crescente papel na economia mundial, e em particular na economia brasileira. Estudos da KPMG Corporate Finance (2003) revelam a ocorrência de 3.196 operações de $F \& A$ no Brasil de 1994 a $2004,58 \%$ das quais com investimento de capital estrangeiro. De acordo com Rossetti (2001), essas transações se intensificaram em função da redução das barreiras de entrada ao capital externo, da inserção do país no mercado global, do fim dos monopólios e das reservas de mercado, da modernização institucional principalmente com as privatizações -, e de problemas em processos sucessórios nas empresas familiares.

O grande número de operações e o novo contexto econômico justificam a busca da compreensão de como se processam as $F \& A$ no país. O s estudos real izados, a maioria com abordagens descritivas e quantitativas, não têm enfocado a análise e a descrição dessas transações, especialmente numa possível influência da cultura brasileira em seu desenvolvimento. Este artigo pretende discutir tais aspectos e as diversas fases dessas operações, entendidas como processos, de forma a relacionar a intenção de compra com as diferentes estratégias de integração no período pós-aquisição. Com a análise de dados dos diversos casos, traça-se um panorama das F\&A no Brasil, avaliando-se "se e de que forma" a cultura local impacta esses processos.

Para isso são discutidos os principais resultados de uma pesquisa quantitativa e qualitativa realizada em
2001, com uma amostra das 500 maiores empresas do país. Essa pesquisa precedente é descrita de forma detal hada no livro Fusões e aquisições no Brasil: entendendo as razões dos sucessos e fracassos, de Barros (2003). ${ }^{1}$ Por meio da análise dos resultados da pesquisa, este artigo avança em termos teóricos ao estabelecer a relação entre os processos de $F \& A$ e a cultura brasileira, ressaltando seus impactos sobre a gestão da integração.

\section{REFERENCIAL TEÓRICO}

\section{Os processos de $F \& A$}

$\mathrm{Na}$ lógica produtiva de um mundo global, formas diversas de relação entre as empresas - desde o relacionamento transacional ao unificado - assumem crescente proporção tanto no nível internacional como no local. Essas relações podem se caracterizar por diferentes tipos de combinação estratégica, exigindo níveis de investimento variados, com formatos legais específicos, e, sobretudo, causar diferentes impactos nas pessoas envolvidas. Segundo Marks e Mirvis (1998) e Barros (2003), esses formatos podem evoluir em um continuum que inicia no simples licenciamento, passando por aliança, parceria e joint venture, e finaliza na operação de fusão e aquisição, conforme mostrado na Figura 1.

A fusão envolve uma combinação completa de duas ou mais empresas, cada uma deixando de existir legalmente para formar uma terceira, com nova identi-

Figura 1 - Diferentes tipos de combinação estratégica

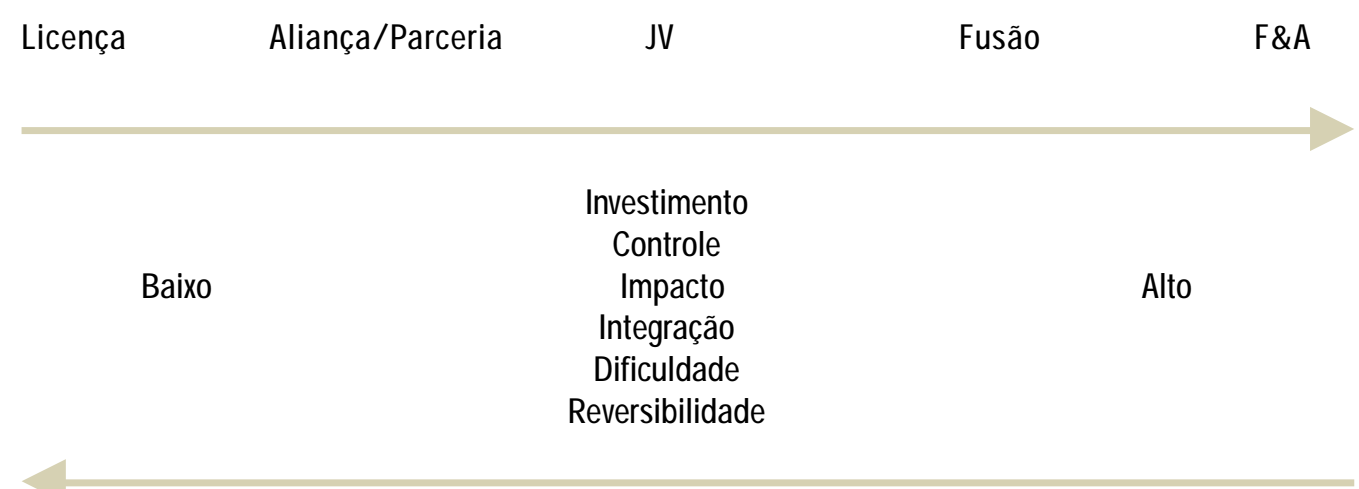


dade. Apesar da suposta igualdade entre os parceiros, o que geral mente ocorre é o controle por parte de um deles. E, de fato, o número de fusões "reais" é tão baixo que, para propósitos práticos, a expressão "fusões e aquisições" basicamente significa aquisições.

$\mathrm{Na}$ aquisição é realizada a compra do controle acionário de uma empresa por outra. Ela representa 0 extremo do continuum da Figura 1, e envolve al to grau de investimentos e de controle, maior impacto sobre a gestão, um processo de integração cultural mais complexo e menor possibilidade de reversibilidade. Essas operações - entendidas como $F \& A$ - ocorrem em etapas consecutivas e interdependentes, que se estruturam a partir da escolha da empresa. À escolha, que envolve a intenção da operação, segue-se a due diligence, a negociação propriamente dita e a integração. É nesse modelo de $F \& A$, entendidas como processos, que 0 artigo concentra sua análise.

Há diversos motivos que levam à $F \& A$. Segundo Lindgren e Spangberg (1981) e Shelton (1988), é buscada uma criação de valor em potencial, por meio da sinergia, partindo-se do pressuposto de que a empresa adquirida irá contribuir estratégica ou financeiramente para a adquirente. Cartwright e Cooper (1999) e Rourke (1992) indicam que a intenção de compra pode estar relacionada à maximização de valor da empresa para o acionista - por meio de economia de escala ou transferência de conhecimento - , à lógica de mercado, ao aumento da participação no mercado, e à redução do nível de incerteza. A intenção de compra pode ainda estar relacionada, quando a empresa possui problemas de desempenho, à necessidade de diversificação pura, de aquisição de tecnologia e de aproveitamento de situações de reestruturação. Para Sterger (1999), os objetivos da F\& A podem ser divididos em dois grupos: 0 primeiro, das "tradicionais", visam à consolidação e à expansão de mercado; e, o segundo, das "transformacionais", o foco é o desenvolvimento de novo portfólio, novo modelo de negócios, ou mudança radical de patamar. As $F \& A$ consideradas transformacionais são mais complexas e requerem muito mais atenção quanto ao processo de integração pósaquisição e à gestão de pessoas.

Uma vez definida a intenção da compra é iniciado o processo de aquisição propriamente dito, começando pela due diligence, quando são realizados levantamentos e anál ises sistematizadas sobre a empresa a ser adquirida. N ormal mente essa etapa é centrada nas análises financeiras decorrentes dos valores relativos a taxas, impostos ou questões legais que influenciam na estrutura da transação em si, com o objetivo de auxiliar na definição do preço a ser pago ( Marks e Mirvis, 1998). Também é comum que a capacidade operacional e a posição mercadológica sejam avaliadas. É importante observar que nessa fase não é dada especial atenção aos recursos humanos ( $\mathrm{RH})$. Profissionais da área não têm participação efetiva nesse período, embora se reconheça a importância da gestão de RH como fator-chave para o êxito dessas operações. Pesquisas realizadas por Evans, Pucik e Barsoux (2002) nos Estados Unidos sustentam essa afirmação, ao indicar que a área de RH está envolvida no planejamento das aquisições em apenas $25 \%$ dos casos, sendo essa participação ainda relativamente maior do que na Europa. Os autores reforçam que é necessária uma auditoria completa do capital humano, contemplando aspectos relativos à qualificação desse patrimônio, identificação de pessoaschave, sistemas de remuneração e questões trabal histas.

$\mathrm{Na}$ etapa de negociação é comum a elaboração de um plano de pré-fechamento da aquisição. Para isso, geralmente é designada uma força-tarefa experiente nesse tipo de operação. Do plano devem constar a estrutura organizacional e hierárquica e a composição do time de integração, definindo-se o seu gestor e 0 cronograma de ações (Evans, Pucik e Barsoux, 2002).

Vários estudiosos concordam que a etapa seguinte desse processo, a integração, é fundamental para garantir o êxito da aquisição. Essa etapa envolve divergências de cultura e, por isso, deve ser cuidadosamente planejada. As perspectivas teóricas sobre a questão da integração cultural são bastante diversas, como se percebe nos trabalhos de Senn (1992), H aspeslagh e Jemison (1991), e, Child, Faulkner e Pitkethly (2001). Partindo dos estudos desses autores e de pesquisas realizadas, Barros $(2001,2003)$ identifica três tipos de aculturação na fase de integração: a assimilação, a mescla, e a pluralidade.

$\mathrm{Na}$ assimilação há uma cultura dominante, observa-se grande mudança na empresa adquirida e pouca na adquirente. A empresa adquirente absorve a outra, impondo seus procedimentos, seus sistemas e sua cultura.

Na mescla há uma convivência de culturas, sem a dominância de uma delas, com moderado grau de mudança em ambas. 0 alcance do equilíbrio na convivência é possível em termos teóricos, mas na prática uma das partes tende a dominar, seja de forma sutil ou ostensiva. Isso não significa que a cultura organizacional predominante não seja alterada pela convivência e pelo questionamento. Desse processo resulta uma terceira cultura. 
$\mathrm{Na}$ pluralidade cultural a adquirente não influencia significativamente a adquirida, e ocorre pouca mudança em ambas. É caracterizada pela convivência de diferentes culturas. Trata-se de um processo transitório, embora não necessariamente breve. Ao longo do tempo, a empresa compradora tende a interferir na adquirida. Na maioria das vezes esse movimento é impulsionado pela introdução de novos sistemas de acompanhamento e de controle, diferentes dos adotados pelas adquirentes.

Em estudos mais recentes foi identificado um quarto tipo de aculturação, denominado movimento reverso (Ghoshal e Tanure, 2004). Ele surge quando a empresa adquirida influencia decisivamente a compradora. Entretanto, essa estratégia ocorre raramente.

A té este ponto foram descritas as diversas etapas de uma aquisição, analisando-se a relevância da fase de integração e o impacto da cultura nesse processo. É importante considerar ainda que a intenção de compra é um dos fatores determinantes da configuração da estratégia de integração. Essa interdependência foi objeto de pesquisas de Barros et al. (2003), e Cançado, Duarte e Costa (2002). Outros fatores observados nessas pesquisas foram a situação financeira da adquirida e a capacidade da adquirente de assumir a gestão, tendo em vista o porte relativo das empresas envolvidas. Todos esses fatores, por sua vez, influenciam o fenômeno de aculturação.

Quando a motivação da compra é classificada como tradicional, relacionada à expansão geográfica, a integração pode se dar por meio de assimilação, com rápida incorporação da adquirida. Se a motivação é transformacional - por exemplo, ligada à aquisição de novas tecnologias -, devem-se preservar as características e 0 modelo de gestão da adquirida, e o processo de integração surge pela pluralidade cultural, mesmo que transitoriamente.

0 trabalho de Barros et al. (2003) reafirma os resultados de pesquisas de Child, Faulkner e Pitkethly (2001), que indicam outras implicações para a gestão de aquisições. O bservam que as características da adquirente - como a nacionalidade e a experiência anterior em operações de aquisição - e da adquirida - como o modelo de gestão, a imagem de mercado e as condições financeiras - têm importantes implicações nas operações internacionais. Os autores demonstram também uma relação entre as estratégias de integração e os vários estilos de gestão, inerentes a cada nacionalidade, como mostra o Quadro 1.

Quadro 1 - Práticas de gestão associadas à nacionalidade da empresa.

\begin{tabular}{|c|c|c|c|c|c|c|c|}
\hline PAÍS & $\begin{array}{l}\text { ORIENTAÇÃO } \\
\text { ESTRATÉGICA }\end{array}$ & ORGANIZAÇÃO & $\begin{array}{l}\text { FORMALI- } \\
\text { ZAÇÃO }\end{array}$ & $\begin{array}{l}\text { INTEGRAÇÃO } \\
\text { DE } \\
\text { SUBSIDIÁRIAS }\end{array}$ & $\begin{array}{l}\text { CARACTERÍSTI- } \\
\text { CAS DOS } \\
\text { CARGOS }\end{array}$ & RECOMPENSA & $\begin{array}{l}\text { GESTÃO DE } \\
\text { CONFLITOS }\end{array}$ \\
\hline $\begin{array}{l}\text { Estados } \\
\text { Unidos }\end{array}$ & $\begin{array}{l}\text { Curto prazo; } \\
\text { financeira }\end{array}$ & $\begin{array}{l}\text { Grau alto; } \\
\text { delegação }\end{array}$ & $\begin{array}{l}\text { Grau alto; pla- } \\
\text { nejamento }\end{array}$ & $\begin{array}{l}\text { Grau alto; via } \\
\text { reporte }\end{array}$ & $\begin{array}{l}\text { Alta mobilida- } \\
\text { de }\end{array}$ & $\begin{array}{l}\text { Ligada à } \\
\text { performance }\end{array}$ & Aberta \\
\hline Japão & $\begin{array}{l}\text { Longo prazo; } \\
\text { relações em } \\
\text { rede }\end{array}$ & $\begin{array}{l}\text { Centralizada, } \\
\text { participativa } \\
\text { (execução), ti- } \\
\text { mes e consenso }\end{array}$ & $\begin{array}{l}\text { Grau baixo, } \\
\text { compartilha- } \\
\text { mento de co- } \\
\text { nhecimento }\end{array}$ & $\begin{array}{l}\text { Grau alto; via } \\
\text { contatos } \\
\text { pessoais }\end{array}$ & $\begin{array}{l}\text { Baixa mobili- } \\
\text { dade; emprego } \\
\text { vitalício }\end{array}$ & $\begin{array}{l}\text { Senioridade; } \\
\text { pequena } \\
\text { diferenciação }\end{array}$ & Fechada \\
\hline Alemanha & $\begin{array}{l}\text { Longo prazo; } \\
\text { melhoria de } \\
\text { produção }\end{array}$ & $\begin{array}{l}\text { Achatada, foco } \\
\text { na posição } \\
\text { formal, mais } \\
\text { participação }\end{array}$ & $\begin{array}{l}\text { Grau alto; pro- } \\
\text { cessos relati- } \\
\text { vamente flexí- } \\
\text { veis }\end{array}$ & $\begin{array}{l}\text { Provavelmen- } \\
\text { te grau médio } \\
\text { (evidência não } \\
\text { muito clara) }\end{array}$ & $\begin{array}{l}\text { Baixa } \\
\text { mobilidade; } \\
\text { especialização } \\
\text { e qualificação }\end{array}$ & $\begin{array}{l}\text { Baseada } \\
\text { em habilida- } \\
\text { des }\end{array}$ & Semi-aberta \\
\hline França & $\begin{array}{l}\text { Estratégica, } \\
\text { mas não de } \\
\text { longo prazo }\end{array}$ & $\begin{array}{l}\text { Grau alto; } \\
\text { estratificada, } \\
\text { baixa } \\
\text { participação }\end{array}$ & Burocrática & $\begin{array}{l}\text { Evidências } \\
\text { sugerem que } \\
\text { seja de grau } \\
\text { alto }\end{array}$ & $\begin{array}{l}\text { Média } \\
\text { mobilidade; } \\
\text { ênfase } \\
\text { especial }\end{array}$ & $\begin{array}{l}\text { Alta diferen- } \\
\text { ciação; } \\
\text { hierárquica }\end{array}$ & Aberta \\
\hline Reino Unido & $\begin{array}{l}\text { Curto prazo; } \\
\text { financeira }\end{array}$ & $\begin{array}{l}\text { Componentes } \\
\text { de gestão }\end{array}$ & $\begin{array}{l}\text { Graumédio;pro- } \\
\text { cedimentos e } \\
\text { planos flexíveis }\end{array}$ & $\begin{array}{l}\text { De grau baixo } \\
\text { a médio }\end{array}$ & $\begin{array}{l}\text { Alta mobilida- } \\
\text { de; mais } \\
\text { generalista }\end{array}$ & $\begin{array}{l}\text { Cada vez mais } \\
\text { ligada à } \\
\text { performance }\end{array}$ & Semi-aberta \\
\hline
\end{tabular}

Fonte: Adaptado de Child, Faulkner e Pitkethly (2001). 
Mais uma vez a cultura influencia essa etapa. As companhias japonesas possuem clara preferência pela pluralidade ou preservação, podendo optar pela mescla. As alemãs transitam nos diferentes tipos, evitando a assimilação. As norte-americanas apresentam tendência à absorção ou assimilação da adquirida. As francesas construíram um estilo diferente, denominado "colonial", com características de centralização, e podem seguir dois caminhos: apontar um diretor com autonomia para tomar decisões depois de discutir com o nível corporativo, ou deixar as decisões estratégicas para o headquarter e o nível de operações por conta da equipe local.

\section{Uma análise da gestão à brasileira}

$\mathrm{N}$ as empresas brasil eiras, apesar dos avanços e da aplicação de técnicas gerenciais de padrão mundial, a racionalidade administrativa é permeada por traços como: informalidade, cordial idade e afetividade; relações de protecionismo e personalismo; instituição do "jeitinho brasileiro" para a resolução de problemas; tendência a evitar conflito; e concentração de poder. As relações pessoais são utilizadas como forma de intermediação em situações de conflito, tratado indiretamente, muitas vezes por meio de fofocas e esquivas de confronto direto com quem detém mais poder (Tanure, 2005).

As origens dessas características podem ser remetidas à época da colonização do país e resultam num comportamento ambíguo de dupla moral e criação de espaços contraditórios. Esse comportamento foi retratado, por exemplo, pel os trabal hos de DaM atta (1990, 1994) e Srour (2000). Para DaM atta, na sociedade brasileira há uma diferença entre o conceito de "indivíduo" (ou o espaço da "rua") e o de "pessoa" (ou o espaço da "casa") . 0 "indivíduo" é visto como um ser anônimo e não é identificado como alguém que faz parte de determinado círculo de relações; portanto, não é digno de atenção ou confiança, sendo tratado absolutamente dentro da expectativa da lei. A "pessoa" é identificada por suas ligações. É merecedora de confiança e possui ampla margem de ação e liberdade. Pelo fato de gozar do prestígio de pertencer a determinado grupo, obtém proteção, o que Ihe possibilita o usufruto das facilidades da lei.

Apesar da existência de leis, regulamentos e normas, os brasileiros convivem no cotidiano com uma discrepância entre a conduta e as normas prescritas. Há processos ou canais extralegais, ou mesmo ilegais, aceitos pelo imaginário coletivo como normais e re- gulares, que visam o atendimento de situações particulares da "pessoa", o que reforça o personalismo. Quanto mais ambíguo o ambiente, melhor é para se exercer o poder de maneira mais forte e personalista (Ramos, 1983). A discrepância é caracterizada como formalismo típico das sociedades "prismáticas" ou em desenvolvimento (Riggs, apud Motta e Alcadipani, 1999). O formalismo, como resultado do caráter dual da formação histórica, a brasileira em particular, é apontado como a principal causa do "jeitinho" brasileiro (Motta e Alcadipani, 1999). Esse "jeitinho" é definido por Motta e Alcadipani (1999, p. 8) como "0 genuíno processo brasileiro de uma pessoa atingir objetivos, a despeito de determinações (leis, normas, regras, ordem, etc.) contrárias". Tal processo não implica corrupção, mas uso de relações pessoais, o que pode ocasionar prejuízos para a coletividade.

Assim, cria-se o amál gama da gestão à brasileira. Tanure (2005) conclui que a gestão à brasileira apresenta aspectos contraditórios, como a flexibilidade para se adaptar a novas situações e a capacidade de lidar com a incerteza, aos quais se interpõe uma forte hierarquia. A flexibilidade se articula com um dos traços marcantes da cultura brasileira: a afetividade. Os brasileiros revelam pensamentos e sentimentos, verbalmente ou não. São acalorados, não se retraem ao toque físico, possuem gestos e expressões fortes, falas fluentes e dramáticas. Esse conjunto de características é refletido no jeitinho, reconhecido pelos estrangeiros que trabal ham no país.

Nas empresas brasileiras pode-se observar também que a absorção de modernas técnicas de gestão apresenta certa submissão a processos importados. 0 comportamento de se orientar pela autoridade externa, presente ainda hoje nos hábitos sociais dos brasileiros - incluída aí a elite -, permite que se importem modelos sem adaptá-los às condições culturais (Tanure, 2005). Isso vem provocando um distanciamento entre o discurso e a prática. 0 discurso é fortemente permeado pela retórica gerencial ista norte-americana, enquanto a prática remete a ambigüidades e peculiaridades características da cultura brasileira. De acordo com Caldas e Wood Jr. (1999, p. 30), "o resultado é uma real idade organizacional de 'faz-de-conta' ou 'para inglês ver'". Isso nos remete novamente ao formalismo. Por outro lado, Wood Jr. e Caldas (1999) apontam que, apesar da adoção dos modelos estrangeiros, pode ocorrer um esforço criativo de releitura e reinterpretação da tecnologia importada, caracterizada como antropofagia organizacional. 
Tanure (2005) al erta que em processos de $F \& A$ não basta 0 apelo à racionalidade compartilhada, porque esta é influenciada e restringida pela nacionalidade. Esse fato precisaria ser anal isado nos empreendimentos globais, pois a origem nacional tem impacto nas questões fundamentais da gestão. A partir da pesquisa empírica anal isada neste artigo, busca-se identificar tais aspectos.

\section{OPERAÇÕES DE F\&A NO BRASIL}

\section{Procedimentos metodológicos}

A fim de melhor compreender como se processam as $F \& A$ no Brasil e alguns aspectos da integração, entre eles a cultura nacional, os dados são de uma pesquisa de cunho quantitativo e qualitativo realizada em 2001 (Barros, 2003). Para o levantamento dos dados quantitativos, a pesquisa usou um questionário, enviado ao principal executivo de cada uma das 500 maiores empresas brasileiras classificadas pela revista Exame (2000), com um retorno de 196 respostas. Em função do critério adotado - a empresa deveria estar envolvida em operações de $F \& A$ no período de 1995 a 2001 -, foram consideradas 106 respostas. A amostra permite traçar um perfil das operações de $F \& A$ em que estão envolvidas grandes empresas do país.

A investigação qualitativa contemplou dez estudos de caso de organizações de diversos setores da economia, selecionadas com base nos seguintes critérios: ser representativas do setor industrial e de serviços; estar envolvidas em diferentes tipos de transação de $F \& A$ transnacional comprando nacional e vice-versa, ou nacional comprando nacional -; ter iniciado a operação no mínimo dois anos e no máximo seis anos antes; permitir acesso à empresa; e disponibilizar dados. Para a elaboração dos casos foram realizadas, em média, 35 entrevistas semi-estruturadas por empresa, com pessoas dos diversos níveis hierárquicos. Neste artigo são analisados os sete casos mais representativos, relativos somente às aquisições.

\section{Análise dos dados}

Com base nas 106 respostas é possível verificar que $28,3 \%$ das empresas tinham faturamento de até $R \$ 200$ milhões, $16 \%$ de $R \$ 201$ milhões a $R \$ 500$ milhões, $23,6 \%$ de $R \$ 501$ milhões a $R \$ 1$ bilhão, e 32,1\% acima de $R \$ 1$ bilhão. De acordo com a classificação de Exame (2000), essas empresas são consideradas megaempresas e possuem as seguintes características: $50 \%$ são de capital privado brasileiro, $44,3 \%$ de capital privado multinacional e $5,7 \%$ de capital estatal. Observa-se certo equilíbrio entre a participação de empresas privadas nacionais e multinacionais em operações de $F \& A$.

Entre 1995 e 2001 o número médio de aquisições por empresa foi 2,72 (variação 1-15). Em grande parte a compra foi realizada pelas seguintes razões vinculadas ao mercado: aumento de participação $(23,4 \%)$, localização geográfica ( $14,3 \%$ ), pen etração em novos mercados $(11,7 \%)$ e aquisição de marcas $(5,2 \%)$. Ganhos de escala motivaram $11,7 \%$ das operações.

Quadro 2 - Motivos da transação.

\begin{tabular}{|c|c|c|c|}
\hline CASO & MOTIVO DA ADQUIRENTE & MOTIVO DA ADQUIRIDA & TIPO DE OPERAÇÃO \\
\hline ABN AMRO/ Banco Real & $\begin{array}{l}\text { Penetração no varejo, mercado } \\
\text { brasileiro }\end{array}$ & $\begin{array}{l}\text { Questão sucessória, incerteza quanto ao } \\
\text { posicionamento no mercado globalizado, } \\
\text { ameaça de mudança na legislação }\end{array}$ & Aquisição \\
\hline $\begin{array}{l}\text { Banco Itaú/ Banco Francês e } \\
\text { Brasileiro }\end{array}$ & $\begin{array}{l}\text { Aquisição de know-how, compe- } \\
\text { tência diferenciada }\end{array}$ & $\begin{array}{l}\text { Problemas financeiros - venda de insti- } \\
\text { tuições na AL }\end{array}$ & Aquisição \\
\hline $\begin{array}{l}\text { Banco Itaú/ Banco do Esta- } \\
\text { do de Minas Gerais, Bemge }\end{array}$ & $\begin{array}{l}\text { Expansão e consolidação geo- } \\
\text { gráfica }\end{array}$ & Privatização & Aquisição \\
\hline $\begin{array}{l}\text { Grupo Belgo-Mineira/ Men- } \\
\text { des Júnior Siderurgia S.A. }\end{array}$ & $\begin{array}{l}\text { Consolidação de posição de mer- } \\
\text { cado no setor }\end{array}$ & Situação financeira precária - dívidas & Aquisição \\
\hline $\begin{array}{l}\text { Carlson Wagonlit Travel } \\
\text { (CWT)/ Agetur }\end{array}$ & $\begin{array}{l}\text { Crescimento, expansão geo- } \\
\text { gráfica }\end{array}$ & Situação financeira precária & Aquisição \\
\hline $\begin{array}{l}\text { Rhodia Silica Systems Bra- } \\
\text { sil/ Venesil }\end{array}$ & $\begin{array}{l}\text { Expansão de mercado na Améri- } \\
\text { ca Latina }\end{array}$ & $\begin{array}{l}\text { Sobrevivência no mercado globalizado, } \\
\text { desvalorização da empresa }\end{array}$ & Aquisição \\
\hline Thyssen/ Sûr & Expansão no Brasil e na AL & Sobrevivência no mercado globalizado & Aquisição \\
\hline
\end{tabular}


Questões de tecnologia tiveram participação menor, $1,3 \%$. Condições de compra muito favoráveis representaram 9,1\% das intenções. Adicionalmente, no que se refere aos motivos da venda, observam-se como predominantes a situação financeira precária (44,6\%) e as boas condições de negociação $(17,6 \%)$.

Portanto, na visão dos executivos de empresas adquirentes, essas empresas estão mais preocupadas com questões de mercado ao adquirir outras organizações, enquanto as que são vendidas são motivadas por condições financeiras ou de transação. Os dados dos casos estudados, apresentados no Quadro 2, confirmam a questão financeira como o principal motivo de venda, relatado por quatro das sete empresas pesquisadas (Banco Francês e Brasileiro, Mendes J r., Agetur e Venesil). Também pode ser percebido o movimento de venda de empresas familiares (Banco Real, Sûr, Agetur, Venesil e M endes Jr. Siderurgia) e os que são resultado de privatização (Bemge).

Embora as decisões sobre a venda ou a compra de uma empresa sejam pautadas pela racional idade e baseadas em projeções quantitativas e informações apresentadas aos acionistas, os dados indicam a dificuldade de grande parte dos proprietários de empresas familiares em considerar o processo de venda de forma mais racional. Certos laços emocionais (por exemplo, anos de sacrifício pessoal e familiar) podem impedir a venda no momento ótimo, ou seja, quando a empresa tem maior valor, como ocorreu na operação da Rhodia com a Venesil. No caso da Elevadores Sûr, as motivações extrapolavam a avaliação financeira. Para 0 exproprietário eram importantes, por exemplo, as crenças e os valores do potencial comprador e o fato de ele ter sido concorrente por anos. Com isso, a empresa não aceitou a oferta mais atrativa financeiramente. $N$ esse caso, 0 adquirente foi o grupo Thyssen.

No que diz respeito à constituição das etapas da operação de aquisição no Brasil, a análise dos casos nos leva a al gumas constatações importantes. Boa parte das operações $(45,4 \%)$ não passou pela fase inicial - a due diligence - de forma estruturada como ocorreu com a compra da Agetur pela Carlson Wagonlit Travel (CWL), cuja proposta não previa essa etapa, e a da $M$ endes Jr. pela Belgo. A M endes estava sob intervenção do Banco Nacional de Desenvolvimento Econômico e Social (BNDES) e em situação de débito.

Em relação à fase seguinte, de negociação, verificase a duração média de 9,2 meses. 0 número médio de profissionais envolvidos é dez participantes da empresa adquirente e oito da adquirida. Essa etapa pode acontecer de manei ra bastante diferenciada e característica para cada empresa. Nessa fase, a área de recursos humanos participou de $20 \%$ das operações e não ocupou posições de decisão na equipe. Tal resultado é similar ao da pesquisa de Evans, Pucik e Barsoux (2002). 0 Quadro 3 resume as características da due diligence e da negociação em algumas operações.

Pelos dados dos estudos de caso, observa-se que em

Quadro 3 - Características da due diligence e da negociação nos casos estudados.

\begin{tabular}{|c|c|}
\hline CASO & DUE DILIGENCE / NEGOCIAÇÃO \\
\hline ABN AMRO/ Banco Real & $\begin{array}{l}\text { Confidencial - segredo; pequena equipe; clima de confiança e cooperação; assinatura de } \\
\text { carta de intenção; proposta formal em mar. } 1998\end{array}$ \\
\hline $\begin{array}{l}\text { Banco Itaú/ Banco Francês } \\
\text { e Brasileiro }\end{array}$ & $\begin{array}{l}\text { Longo e complexo; designação de uma equipe especializada pelo Itaú: coordenador e um } \\
\text { executivo de cada área do banco; carta de intenção; contrato em out.1995 }\end{array}$ \\
\hline $\begin{array}{l}\text { Banco Itaú/ Banco do Estado de Mi- } \\
\text { nas Gerais, Bemge }\end{array}$ & $\begin{array}{l}\text { Data room; equipe de profissionais para avaliação - média de } 40 \text { pessoas, metodologia e } \\
\text { critérios bem definidos. Leilão em set. } 1998\end{array}$ \\
\hline $\begin{array}{l}\text { Grupo Belgo Mineira / Mendes Júnior } \\
\text { Siderurgia S.A. }\end{array}$ & $\begin{array}{l}\text { Situação de débito negociada pelo BNDES e pelo governo do Estado de Minas Gerais; } \\
\text { decisão rápida; negociação durou quatro meses }\end{array}$ \\
\hline $\begin{array}{l}\text { Carlson Wagonlit Travel } \\
\text { (CWT)/ Agetur }\end{array}$ & $\begin{array}{l}\text { Modelo earn out, sem etapa de due diligence; negociações conduzidas por um executivo da } \\
\text { CWT e um da Agetur; carta de intenção de caráter sigiloso; contrato assinado em dez. } 2000\end{array}$ \\
\hline $\begin{array}{l}\text { Rhodia Silica Systems } \\
\text { Brasil/ Venesil }\end{array}$ & $\begin{array}{l}\text { Processo longo, duro e complicado; primeira abordagem na década de 1990: vencer resis- } \\
\text { tência do proprietário; inúmeras delegações; equipe de negociação formada por profissio- } \\
\text { nais da Rhodia e dois representantes da VenesilVenesil, com participação direta do propri- } \\
\text { etário; contrato assinado em out. } 2000\end{array}$ \\
\hline Thyssen/ Sûr & $\begin{array}{l}\text { Clima de confiança, transparência e honestidade; pequeno número de executivos de am- } \\
\text { bos os lados; contrato em set. } 1999\end{array}$ \\
\hline
\end{tabular}


certas situações a negociação pode ser extremamente profissional izada e estruturada, tendo à frente executivos que possuem a especialização necessária para conduzir o processo e preparo para lidar com situações adversas. Foi o que ocorreu no Banco Itaú. Há também a possibilidade de um processo mais personalizado, com o proprietário conduzindo a negociação pessoalmente, como no caso da Venesil, ou delegando-a para outras pessoas de sua confiança, como no caso do Banco Real.

Nos relatos é possível identificar a necessidade de determinação e perseverança por parte dos profissionais envolvidos nessa etapa de negociação. Na maioria das vezes o período é longo e estressante. $N$ ota-se que 0 envolvimento emocional pode se sobrepor à racionalidade quando o dono está à frente da negociação. Além do prolongamento dessa etapa, esse comportamento pode levar a uma redução do nível de investimento na empresa, à evasão de talentos e à desatenção com a manuten ção da carteira de clientes.

Os primeiros passos para a integração cultural são dados durante a etapa da negociação. Pode-se observar que o relacionamento estabelecido nesse período entre os parceiros é a base para a nova etapa.

Acerca do planejamento da integração, $48,3 \%$ dos respondentes do questionário informaram que ela ocorreu de maneira natural e espontânea, sem a designação de grupos-tarefa. Quando houve alocação de pessoas para conduzir a integração, verificou-se a predominância de equipes formadas por até cinco indivíduos. Em somente quatro empresas as equipes tinham mais de 20 pessoas. Houve contratação de consultoria externa para apoio a essa fase em $25,3 \%$ dos casos.

A estratégia predominante de integração cultural foi a assimilação, com índice de 58,1\%. A mescla ocorreu em $37,8 \%$ das operações e a plural idade em $4,1 \%$. Para $65,1 \%$ da amostra, a forma adotada foi a intencional, para $57 \%$ estava se processando no nível de complexidade esperado e para $61 \%$ a etapa de integração estava concluída. Em média, o período de integração foi de 24 meses. Algumas similaridades e diferen ças entre os diversos processos são mostradas no Quadro 4, a partir dos dados dos estudos de caso.

N os casos apresentados, observa-se a influência da condição financeira da adquirida na estruturação da estratégia. Essa influência foi relatada por Child, Faulkner e Pitkethly (2001). A Agetur e a Venesil estavam com a situação financeira frágil na época da operação, e suas adquirentes (respectivamente CWT e Rhodia) optaram pela assimilação. Fato semelhan- te ocorreu na compra da M endes Jr. pela Belgo, embora nesse processo a estratégia, também de assimilação, tenha se definido de forma muito gradativa. A simples melhoria de eficiência da adquirida também pode levar a essa forma de integração, adotada pelo Banco I taú na compra do Banco do Estado de Minas Gerais (Bemge). Em empresas que se encontravam em boa situação financeira e que foram compradas com o objetivo de obter know-how, como o Banco Real e a Sûr, a estratégia de integração visou a preservação de competências, tendendo à pluralidade e/ou à mescla.

Correlacionando os dados do Quadro 4 com os do Q uadro 2, é possível analisar a relação entre a motivação de compra e a forma de integração implementada. Esses achados reforçam as conclusões de Barros et al. (2003) e de Child, Faulkner e Pitkethly (2001) sobre a importância da adequação da estratégia de integração à motivação de compra. Um exemplo dessa perspectiva pode ser visto em operações do Banco I taú. $\mathrm{Na}$ aquisição do Banco Francês e Brasileiro (BFB), desejava-se adquirir competência no atendimento a determinado segmento de clientes e na oferta de produtos diferenciados, tecnologia não dominada pelo I taú. A integração foi efetivada via pluralidade. $\mathrm{Na}$ aquisição do Bemge, a necessidade de ampliar o mercado de atuação, especialmente em Minas Gerais, levou o Itaú a estruturar a rápida assimilação. O bserva-se nas operações do Itaú que a experiência prévia em aquisições levou à construção de um know-how diferenciado, com a designação de equipes especializadas tanto para a due diligence como para a negociação, além do planejamento da fase de integração. Dessa forma, reforçouse a assertiva da importância da experiência prévia em operações de $F \& A$, de Child, Faulkner e Pitkethly (2001).

É possível observar ainda que metade das empresas adquiridas era familiar e tinha características de gestão mais informal e personalizada (Agetur, M endes Jr., Banco Real e Sûr). A Venesil, localizada na Venezuela, também apresenta traços similares aos das empresas brasileiras em termos de gestão familiar. $\mathrm{Na}$ fase de integração, conduzida por executivos da Rhodia Brasil, visou-se "agregar ao espírito Rhodia a união e a informalidade, pontos fortes da Venesil".

No processo de integração se verificou o respeito por parte das adquirentes, normalmente mais profissionalizadas, de características e hábitos das adquiridas, incorporando aspectos mais ligados à informalidade e ao relacionamento interpessoal. Disso resulta 
Quadro 4 - Aspectos relacionados à fase de integração.

\begin{tabular}{|l|l|l|l|}
\hline \multicolumn{1}{|c|}{ CASO } & \multicolumn{1}{|c|}{ TIPO } & \multicolumn{1}{|c|}{ PRIORIDADE } & $\begin{array}{c}\text { SISTEMAS/ } \\
\text { PROCESSOS DE } \\
\text { TRABALHO }\end{array}$ \\
\hline $\begin{array}{l}\text { ABN AMRO/ } \\
\text { Banco Real }\end{array}$ & $\begin{array}{l}\text { Pluralidade na } \\
\text { fase 1, mescla } \\
\text { na fase 2 e no } \\
\text { segmento cor- } \\
\text { porativo }\end{array}$ & $\begin{array}{l}\text { Proposta de respeito, } \\
\text { transição lenta, com } \\
\text { a formação de equi- } \\
\text { pes de trabalho }\end{array}$ & $\begin{array}{l}\text { Sistemas de con- } \\
\text { trole do ABN e im- } \\
\text { plantação gradati- } \\
\text { va do modelo de } \\
\text { gestão próprio }\end{array}$ \\
\hline $\begin{array}{l}\text { Banco Itaú/ } \\
\text { Banco Fran- } \\
\text { cês e Brasilei- } \\
\text { ro }\end{array}$ & $\begin{array}{l}\text { Pluralidade na } \\
\text { fase 1 do Per- } \\
\text { sonnalité, mes- } \\
\text { cla no Société }\end{array}$ & $\begin{array}{l}\text { Preservação compe- } \\
\text { tências e de carteira } \\
\text { de clientes; reorgani- }\end{array}$ & $\begin{array}{l}\text { Padronização do } \\
\text { zack ostrutural; cin- } \\
\text { co anos. }\end{array}$ \\
$\begin{array}{l}\text { mecanismos com de } \\
\text { controle pelo Itaú }\end{array}$ \\
\hline $\begin{array}{l}\text { Banco Itaú/ } \\
\text { Banco do Es- } \\
\text { tado de Minas } \\
\text { Gerais, Bemge }\end{array}$ & $\begin{array}{l}\text { Assimilação } \\
\text { Implantar sistemas } \\
\text { operacionais e pro- } \\
\text { cessos do Itaú; reor- } \\
\text { ganização estrutural }\end{array}$ & $\begin{array}{l}\text { Rápida mudança } \\
\text { de bandeira, dos } \\
\text { processos de tra- } \\
\text { balho e do mode- } \\
\text { lo de gestão, nos } \\
\text { moldes do Itaú }\end{array}$ \\
\hline $\begin{array}{l}\text { Grupo Belgo/ } \\
\text { Mendes } \\
\text { Júnior } \\
\text { Siderurgia } \\
\text { S.A. }\end{array}$ & $\begin{array}{l}\text { Assimilação } \\
\text { gradativa }\end{array}$ & $\begin{array}{l}\text { Retomada da opera- } \\
\text { ção da usina; melho- } \\
\text { ria do clima, com } \\
\text { resgate da auto-esti- } \\
\text { ma; reorganização } \\
\text { paulatina }\end{array}$ & $\begin{array}{l}\text { Projeto de rees- } \\
\text { truturação } \\
\text { Belgo, implantado } \\
\text { em etapas nego- } \\
\text { ciadas em função } \\
\text { do } \\
\text { comodelo de } \\
\text { compra }\end{array}$ \\
\hline
\end{tabular}

\begin{tabular}{l|l} 
Carlson & Assimilação \\
WagonlitTravel \\
(CWT)/ Agetur
\end{tabular}

Rhodia Sílica Assimilação

Systems

Brasil/ Venesil

Thyssen/ Sûr Pluralidade
Implantação dos sistemas operacionais; reorganização básica em seis meses
Implantação do sistema operacional Sabre e treinamento do pessoal; integração das duas equipes valores da corporação mundial; implantação de processos e controles de forma respeitosa

Implantação lenta e gradativa de sistemas de controle; não-reorganização da estrutura
Disseminação dos
Implantação do sistema contábil e financeiro; revisão dos processos de produção industrial e de qualidade

Sistemas de Formal, hierarquiacompanhamen- zada, "monárquito financeiro - ca". EVA; ferramentas gerenciais corporativas

Valores explicitados; processos de trabalho e sistemas de controle estruturados em nível corporativo.

\section{GESTÃO DA ADQUIRENTE}

Orientada para resultados; transparência, busca de consenso, descentralização e lealdade à empresa

Processos sistematizados, em manuais, decisões pautadas pela racionalidade; orientada para resultados; estrutura hierarquizada

Empresa mais organizada, funciona com planejamento; estilo conservador em termos de negócios

Empresa marcada por diversas aquisições (um mosaico de culturas); empresa mais centralizada e burocratizada
GESTÃO DA

ADQUIRIDA

Traços da cultura brasileira: centralização, paternalismo, lealdade às pessoas, evitação de conflitos

Menor sistematização dos processos, alta criatividade, autonomia nas decisões

Banco estatal, pouco voltado para cliente e para resultados. Política de apadrinhamento.

Empresa familiar; prestação de serviços para o governo; moderna, tecnologicamente avançada; bons salários, investimentos em RH

Uma das empresas de um grupo familiar com atuação em transportes; grande "mãe"; presença marcante do

Empresa familiar, personalística, baseada em simplicidade, informalidade e relacionamento pessoal

\section{Cultura familiar, in-
formalidade nas
relações, espírito
de inovação e au-
dácia; agilidade Cultura familiar, in-
formalidade nas
relações, espírito
de inovação e au-
dácia; agilidade Cultura familiar, in-
formalidade nas
relações, espírito
de inovação e au-
dácia; agilidade Cultura familiar, in-
formalidade nas
relações, espírito
de inovação e au-
dácia; agilidade Cultura familiar, in
formalidade nas
relações, espírito
de inovação e au-
dácia; agilidade} daia; agilade proprietário

\section{MODELO RESULTANTE}

Modelo de gestão mais participativo, tendo como premissa a sustentabilidade dos resultados

Modelo híbrido, baseado nas características das duas empresas e da nova gestão

Gestão voltada para o mercado, com foco no cliente; processos racionalizados

Construção de nova empresa, de nova mentalidade - "Belgo de Juiz de Fora" -; coordenação corporativa por meio do SAP

Tendência a homogeneizar a empresa; dificuldade de integração em função do grande tamanho da adquirida

Dominação brasileira aceita - gestão mais participativa, preservando algumas características locais

Alinhamento gradativo aos novos proprietários (empresa global, foco em resultados) 
um modelo híbrido de gestão, que integra processos racionalizados e o jeitinho brasileiro. Então, ficam duas questões a estudar: a) a cultura e a nacionalidade da adquirida exercem também influência sobre a forma de integração e a conseqüente construção do novo model o de gestão?; b) além de esse processo ter características inerentes à nacional idade da adquirente, conforme o trabal ho de Child, Faulkner e Pitkethly (2001), aspectos da cultura local e da adquirida também teriam peso no estabelecimento da fase de integração e na construção da nova identidade organizacional?

\section{CONSIDERAÇÕES FINAIS}

Espera-se que, diante da escassez de estudos sistemáticos sobre $F \& A$ no Brasil, a presente discussão que teve como base os dados da pesquisa realizada por Barros (2003) - tenha atendido aos objetivos de descrever e demonstrar como ocorrem essas operações no país. Esses dados demonstram al gumas especificidades que podem estar ligadas a características inerentes à cultura brasileira.

Partindo-se de considerações sobre a cultura brasileira, buscou-se nesta discussão apresentar as semeIhanças entre os processos de $F \& A$, bem como suas especificidades. Para isso, analisa-se o impacto das características da gestão à brasileira, com base nos dados mais rel evantes do levantamento e dos estudos de caso apresentados. 0 foco dessa discussão está na argumentação de que os processos de $F \& A$ no Brasil, apesar de seguirem aspectos postulados pela teoria, acabam por ganhar contornos específicos, impregnando-se de um estilo próprio em função de características marcantes da cultura local.

É importante ressaltar que, em todos os casos apresentados, as empresas adquirentes já tinham conhecimento e experiência de gestão na realidade brasileira, o que pode, de certa forma, explicar al gumas especificidades. O Banco Itaú é genuinamente brasileiro; a Belgo opera no Brasil desde o início do século passado; o ABN esteve presente na América Latina também desde o século passado, e teve o apoio de um executivo brasileiro na condução de todo o processo; a CWL, apesar do pouco tempo de Brasil, contou com a experiência anterior do grupo Accor no país; e tanto a Rhodia quanto a Thyssen já tinham atividades no país antes das operações realizadas.

Em relação aos dados do estudo quantitativo, considerando que as operações de $F \& A$ no Brasil se in- tensificaram na década de 1990 e que mais da metade da amostra participou de apenas um processo, constata-se que as empresas brasileiras não possuem experiências anteriores importantes em $F \& A$. Observa-se ainda que as maiores empresas tendem a comprar as de menor porte, corroborando a afirmação de Evans, Pucik e Barsoux (2002) de que comprar empresas menores é uma postura típica de ganhadores.

$A$ inexperiência nos processos de $F \& A$ e 0 caráter de informalidade típico do Brasil podem estar relacionados ao fato de $45,4 \%$ das empresas pesquisadas não terem passado pela due diligence e de $48,3 \%$ terem afirmado que não houve um planejamento da etapa de integração. Por outro lado, 31\% consideraram o estudo detalhado do negócio como o mais importante fator de sucesso de uma operação de $F \& A$. Assim, é evidenciado um caráter dúbio: ao mesmo tempo em que os executivos sabem e atribuem importância ao planejamento, o mesmo não é praticado, talvez devido ao próprio estilo brasileiro, de característica mais informal e menos racional.

Entretanto, observa-se também que, à medida que as empresas adquirem maior experiência, como no caso do Itaú, é possível desenvolver equipes especializadas e know-how específico, que auxiliam na efetivação da operação. Desse modo, os resultados da pesquisa de Child, Faulkner e Pitkethly (2001) são corroborados, ao indicar-se a existência de uma rel ação entre a experiência anterior, o tipo de intervenção e a atuação da adquirente.

Em resumo, conforme relato dos dirigentes consultados, é possível afirmar que no Brasil quase metade das operações não inclui a due diligence, a etapa de negociação é de 3 a 12 meses, a etapa de integração é de cerca de dois anos, e quase metade da amostra não realiza o planejamento. Assim, pode-se considerar que, em termos teóricos, atribui-se importância à due diligence, à negociação e ao planejamento da integração cultural, mas na prática essas fases não são muito sistematizadas.

$\mathrm{N}$ a due diligence, a exemplo da real idade norte-americana e da européia, há uma pequena participação da área de recursos humanos, e quando isso ocorre os profissionais não ocupam posições de decisão na equipe. Os dados dos estudos de caso reafirmam essa perspectiva, indicando o foco nas avaliações financeiras e a au sência ou pequena preocupação com a análise - antes que a operação se efetive - da cultura da empresa a ser adquirida. Reforça-se a necessidade de atentar para essa etapa no Brasil, contemplando-se, além do ma- 
peamento cultural, uma auditoria completa do capital humano, o que se traduz em qualificação do patrimônio humano, identificação de pessoas-chave e avaliação dos sistemas de remuneração. As questões trabaIhistas não devem ser as únicas a serem consideradas. Informações relevantes sobre os recursos humanos são úteis no planejamento da etapa de integração, al ém de fornecerem uma perspectiva mais realista da empresa a ser adquirida, ultrapassando-se a aval iação meramente financeira.

Outro aspecto relativo às etapas e que merece ser discutido é o prolongamento do processo de negociação diante do envolvimento nessa fase do proprietário da empresa a ser comprada. Como a maior parte das empresas adquiridas, analisadas nos estudos de caso, é de origem familiar, a dificuldade de se chegar a decisões racionais na venda pode se relacionar aos laços afetivos do dono com o negócio e com os empregados. Essa questão pode estar exacerbada no Brasil em função das características de relações de proteção e dependência historicamente construídas. Cabe ao proprietário da empresa proteger seus "filhos", sendo que a venda do negócio pode ser vista como abandono e traição do "pai". N esse cenário, muitas vezes se perde o momento ótimo da venda.

Dessa forma, um dos desafios das operações de $F \& A$, principalmente no Brasil, é o desenvolvimento adequado das fases, respeitando-se as características locais. Para tal, são fundamentais a correta avaliação estratégica - seja do comprador ou do vendedor -, a qualidade das informações obtidas na due diligence, a definição prévia de uma estratégia de integração que considere o universo de atores envolvidos, a indicação de negociadores com base na estratégia escolhida e a identificação dos interlocutores e seus perfis. Além desses aspectos racionais, é importante considerar os ligados à cultura brasileira, que são o cultivo de relações pessoais como base da relação de confiança, e o entendimento da ambigüidade e da dualidade. 0 resultado dessa etapa impacta diretamente a integração.

A análise dos estudos de caso permite também reforçar as conclusões de estudos anteriores realizados por Ghoshal e Tanure (2004), Barros et al. (2003) e Child, Faulkner e Pitkethly (2001), nos quais se percebeu a importância da adequação da estratégia de integração à motivação de compra e à situação da adquirida. Observa-se que a assimilação está mais relacionada às motivações ligadas ao mercado - penetração ou expansão geográfica - e a situações de crise das empresas adquiridas. Em operações voltadas à obtenção de tecnologia ou de know-how, ou quando a adquirida se encontrava em boa situação financeira, ou ainda apresentava uma estrutura maior do que a local da adquirente, buscou-se preservar suas características, e a integração se deu via pluralidade e/ou mescla.

Final mente, revela-se ainda que na maioria das empresas adqui ridas prevalecem os traços da gestão à brasileira como anteriormente discutidos. Assim, os processos de gestão são sistematizados mas não focados prioritariamente em resultados; há uma centralização na figura do proprietário ou seu representante; e uma gestão paternalista, baseada na informalidade, na simplicidade e em relacionamentos personalizados. As empresas adquirentes se mostram mais profissionali-

Figura 2 - Modelo de análise: 0 impacto da cultura em processos de aquisição

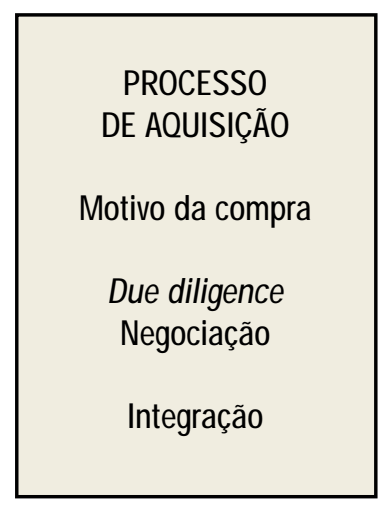

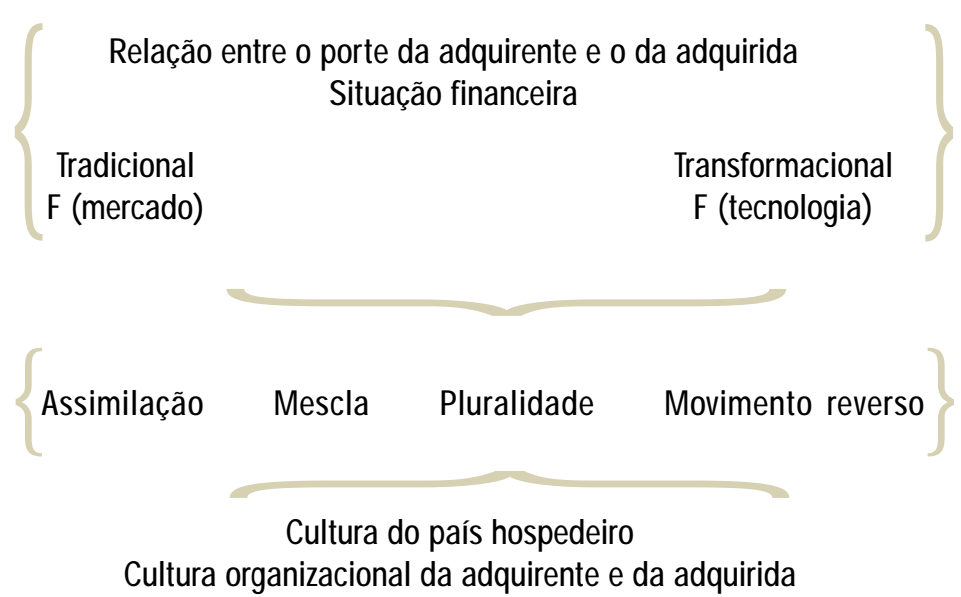

Cultura organizacional da adquirente e da adquirida 
zadas, com sistemas mais formais e estruturados, e mais orientadas para resultados. Pode-se traçar um continuum que vai de um maior grau de profissionalização nas adquirentes até uma gestão personalizada nas adquiridas. De um lado, a adquirida implementa as práticas racional izadas da compradora; de outro, 0 ambiente "de grande família" existente anteriormente na adquirida é recon hecido pela compradora, que procura formas de incorporá-lo às suas práticas racionalizadas. Surge então um novo modelo de gestão que considera a eficiência e a eficácia dos processos racionalizados e a efetividade do espaço "pessoal", tão caro à cultura brasileira.

Com base nesta análise, pode-se propor um modelo teórico no qual se destaca o conceito de aquisição como um processo que ocorre em fases interdependentes e relacionadas, que sofrem o impacto da cultura do país hospedeiro e de suas especificidades de gestão, conforme apresentado na Figura 2.

Ao mesmo tempo em que pesquisas reforçam a idéia de que a nacionalidade da adquirente imprime aspectos peculiares à efetivação das operações de $F \& A$ - os americanos tendem à assimilação, enquanto os al emães evitam essa estratégia; os japoneses tendem à pluralidade e à mescla e os franceses apresentam o estilo "colonial" -, os resultados das análises aqui apresentados indicam ser necessário dirigir a atenção para a cultura da empresa adquirida. Independentemente da nacionalidade da adquirente, todas as fases dessas operações no Brasil, principalmente a negociação e a integração, são permeadas pelos traços de afetividade e personalização, característicos da cultura do país, em contraposição à racionalidade preconizada. Portanto, evidencia-se a necessidade de atentar não apenas para a nacional idade da adquirente, mas também da adquirida. Desse modo, fazer negócios no Brasil pode implicar a aceitação e a incorporação do estilo de gestão à brasileira.

\section{NOTA}

${ }^{1}$ A partir de 2004 a autora passou a adotar o sobrenome Tanure para suas publicações. Essa obra será reeditada com Tanure como autora.

\section{REFERÊNCIAS BIBLIOGRÁFICAS}

BARROS, B. T. Fusões e aquisições no Brasil: entendendo as razões dos sucessos e fracassos. São Paulo: Atlas, 2003.
BARROS, B. T. et al. Criando valor com aquisições: por que comprar? Como integrar? 0 caso do Banco Itaú. In: EN CONTRO NACIONAL DE ESTUDOS ORGANIZACIONAIS, 27., 2003, São Paulo. Anais. São Paulo: ANPAD, 2003.

BARROS, B. T.; CANÇADO, V. L. Aquisições: um perfil das operações no Brasil. In: IBEROAMERICAN ACADEMY OF MANAGEMENT: INTERnational CONFERENCE, 2003, São Paulo. Anais. São Paulo, 2003.

BARROS, B. T. (O rg.). Fusões, aquisições e parcerias. São Paulo: Atlas, 2001.

CALDAS, M. P.; W OOD JR., T. Para inglês ver: a importação de tecnologia gerencial no Brasil. In: CALDAS, M. P.; WOOD JR., T. Transformação e realidade organizacional: uma perspectiva brasileira. São Paulo: Atlas, 1999.

CANÇADO, V. L.; DUARTE, R. G.; COSTA, K. F. Processo de mudanças no período pós-F\& A: o caso ABB/M ontes Claros. In: CLADEA, 37., 2002, Porto Alegre. Anais. Porto Alegre: CLADEA, 2002.

CARTWRIGHT, S.; COOPER, C. L. Managing Mergers, Acquisitions \& Strategic Alliances: Integrating People and Cultures. Oxford: Butterworth Heinemann, 1999.

CHILD, J.; FAULKNER, D.; PITKETHLY, R. The M anagement of International Acquisitions: Realizing Their Potential Value. New York: Oxford University Press, 2001.

DAMATTA, R. Carnavais, malandros e heróis: para uma sociologia do dilema brasileiro. Rio de Janeiro: Guanabara, 1990.

DAMATTA, R. 0 que faz o Brasil, Brasil? Rio de Janeiro: Rocco, 1994.

DUARTE, R. G. Cross-border Acquisitions and Changes in Domestic M anagement Practices: The Case of Brazil. Centre for International Business and Management, Queen's College, Cambridge, 2001. (Thesis Ph.D. degree.).

EVANS, P.; PUCIK, V.; BARSOUX, J.-L. The Global Challenge: Frameworks for International Human Resource M anagement. Boston: McGraw-Hill, 2002.

GHOSHAL, S.; TANURE, B. Estratégia e gestão empresarial: construindo empresas brasileiras. Rio de Janeiro: Campus, 2004.

HASPESLAGH, P. C.; JEMISON , D. B. M anaging Acquisitions: Creating Value through Corporate Renewal. N ew York: Free Press, 1991.

KPMG CORPORATE FINANCE. Pesquisa sobre fusões e aquisições: operações realizadas no Brasil. Disponível em: 〈http://www.kpmg.com.br/adm/ images/FA\%204.trim_03\%20B.pdf>. Acesso em: 13 abr. 2004.

LINDGREN, U.; SPANGBERG, K. Management of the post-acquisition process in diversified MNCs. In: Otterberck, L. (Ed.). The M anagement of Headquarters: Subsidiary Relationships in Multinational Corporations. Aldershot: Gower, 1981.

MARKS, M. L.; MIRVIS, P. H. Joining Forces: Making One Plus One Equal Three in M erger, Acquisitions, and Alliances. San Francisco: Jossey-Bass, 1998. 
MOTTA, F. C. P.; ALCADIPANI, R. 0 jeitinho brasileiro, controle social e competição. Revista de Administração de Empresas. v. 39, n. 1, p. 6-12, 1999.

RAMOS, A. G. Administração e contexto brasileiro. 2. ed. Rio de Janeiro: FGV, 1983.

REVISTA EXAME. Exame: melhores e maiores. São Paulo: Jun. 2000.

ROSSETTI, J. P. Fusões e aquisições no Brasil: as razões e os impactos. In: BARROS, B. T. (Org.). Fusões, aquisições e parcerias. São Paulo: Atlas, 2001. cap. 3, p. 76-87.

ROURKE, J. T. Integração pós-fusão. In: KEY, S. L. Guia da Ernst \& Young para administração de fusões e aquisições. Rio de Janeiro: Record, 1992. p. 13-32.

SENN, L. Cultura. In: KEY, S. L. Guia da Ernst \& Young para administração de fusões e aquisições. Rio de Janeiro: Record, 1992. p. 17-31
SHELTON, L. M. Strategic business and corporate acquisition: empirical evidence. Strategic Management Journal, v. 9, n. 3, p. 279-287, 1988.

SROUR, R. H. Ética empresarial: posturas responsáveis nos negócios, na política e nas relações pessoais. Rio de Janeiro: Campus, 2000.

STEGER, U. The transformational merger. Financial Times Mastering Management Review, London, v. 30, p. 46-50, 1999.

TANURE, B. Gestão à brasileira: uma comparação entre América Latina, Estados Unidos, Europa e Ásia. 2. ed. São Paulo: Atlas, 2005.

W OOD JR., T.; CALDAS, M. P. Antropofagia organizacional. In: CALDAS, M. P, W OOD JR., T. Transformação e realidade organizacional: uma perspective brasileira. São Paulo: Atlas, 1999.

UNITED NATIONS CONFERENCE ON TRADE AND DEVELOPMENT. World Investment Report 2000: Cross-border Mergers and Acquisitions and Development. New York: United Nations, 2000.

\section{Artigo recebido em 24.06.2004. Aprovado em 04.03.2005.}

\section{Betania Tanure}

Professora e pesquisadora da Fundação Dom Cabral e PUC-Minas. Doutora em Administração.

Interesses de pesquisa nas áreas de gestão internacional, estratégias de gestão de pessoas, cultura e mudança, estresse e qualidade de vida no trabal ho, estratégia e gestão empresarial.

E-mail: betaniat@fdc.org.br

Endereço: Rua Prof. Eugênio Murilo Rubião, 33, ap. 202, Anchieta, Belo Horizonte- Minas Gerais, 30310-540.

\section{Vera L. C ançado}

Professora e pesquisadora da Fundação Dom Cabral e Fundação Pedro Leopoldo. Doutora em Administração. Interesses de pesquisa nas áreas de gestão internacional, estratégias de gestão de pessoas e comportamento humano nas organizações.

E-mail: vcancado@uai.com.br

Endereço: Rua Fernando Esquerdo, 35, ap. 303, Gutierrez, Belo Horizonte - M inas Gerais, 30430-300. 